\title{
Polyurea-Functionalized Multiwalled Carbon Nanotubes: Synthesis, Morphology, and Raman Spectroscopy
}

\author{
Chao Gao, ${ }^{*}, \sharp$ Yi Zheng Jin,, Hao Kong, ${ }^{\dagger}$ Raymond L. D. Whitby, Steve F. A. Acquah, \\ G. Y. Chen, ${ }^{\S}$ Huihong Qian," Achim Hartschuh," S. R. P. Silva, ${ }^{\S}$ Simon Henley, ${ }^{\S}$ Peter Fearon," \\ Harold W. Kroto, ${ }^{\ddagger+}$ and David R. M. Walton* \\ College of Chemistry and Chemical Engineering, Shanghai Jiao Tong University, 800 Dongchuan Road, \\ Shanghai 200240, People's Republic of China, Department of Chemistry, School of Life Sciences, University of \\ Sussex, Brighton BN1 9QJ, United Kingdom, Advanced Technology Institute, School of Electronics and \\ Physical Sciences, University of Surrey, GU2 7XH, United Kingdom, Universitaet Siegen, Physikalische \\ Chemie I, Adolf-Reichwein-Strasse 2, D-57068 Siegen, Germany, and Department of Chemistry and \\ Biochemistry, The Florida State University, Tallahassee, Florida 32306-4390
}

Received: March 31, 2005; In Final Form: April 25, 2005

\begin{abstract}
An in situ polycondensation approach was applied to functionalize multiwalled carbon nanotubes (MWNTs), resulting in various linear or hyperbranched polycondensed polymers [e.g., polyureas, polyurethanes, and poly(urea-urethane)-bonded carbon nanotubes]. The quantity of the grafted polymer can be easily controlled by the feed ratio of monomers. As a typical example, the polyurea-functionalized MWNTs were measured and characterized in detail. The oxidized MWNTs (MWNT-COOH) were converted into acyl chloridefunctionalized MWNTs (MWNT-COCl) by reaction with neat thionyl chloride $\left(\mathrm{SOCl}_{2}\right)$. $\mathrm{MWNT}-\mathrm{COCl}$ was reacted with excess 1,6-diaminohexane, affording amino-functionalized MWNTs $\left(\mathrm{MWNT}-\mathrm{NH}_{2}\right)$. In the presence of $\mathrm{MWNT}-\mathrm{NH}_{2}$, the polyurea was covalently coated onto the surfaces of the nanotube by in situ polycondensation of diisocyanate [e.g., 4,4'-methylenebis(phenylisocyanate)] and 1,6-diaminohexane, followed by the removal of free polymer via repeated filtering and solvent washing. The coated polyurea content can be controlled to some extent by adjusting the feed ratio of the isocyanato and amino groups. The structure and morphology of the resulting nanocomposites were characterized by FTIR, NMR, Raman, confocal Raman, TEM, EDS, and SEM measurements. The polyurea-coated MWNTs showed interesting self-assembled flator flowerlike morphologies in the solid state. The signals corresponding to that of the D and G bands of the carbon nanotubes were strongly attenuated after polyurea was chemically tethered to the MWNT surfaces. Comparative experiments showed that the grafted polymer species and structures have a strong effect on the Raman signals of polymer-functionalized MWNTs.
\end{abstract}

\section{Introduction}

Functionalization or modification of nanosurfaces has unlocked a new era in the development and applications of hybrid nanomaterials. ${ }^{1}$ Binding polymers to carbon nanotubes $(\mathrm{CNTs})^{2}$ promises to be one of the most intriguing prospects in this technology because the individual properties of the two materials can be combined to give one novel hybrid nanomaterial with good mechanical strength, high thermal conductivity, and excellent processing ability. ${ }^{3}$ This can be generally achieved by the grafting to ${ }^{4}$ and grafting from ${ }^{3,5}$ approaches. The former involves direct reaction of existing polymers containing terminal functional groups (e.g., $-\mathrm{OH}$ and $-\mathrm{NH}_{2}$ ) with the anterior functional groups (e.g., $-\mathrm{COOH}$ and $-\mathrm{COCl}$ ) on $\mathrm{CNTs}$, either in solution or by melt-compounding. ${ }^{4,6}$ The apparent limitation of the grafting to approach lies in the specific requirement of

* Corresponding author. Tel: +86-21-5474 2665; fax: +86-21-5474 1297; e-mail: chaogao@sjtu.edu.cn.

Shanghai Jiao Tong University.

$\doteqdot$ University of Sussex

$\S$ University of Surrey.

"Universitaet Siegen.

+ The Florida State University. the polymer terminal functional groups, the low grafting density, and the limited control over the grafted polymer content. The grafting from approach, involving in situ polymerization of monomers from CNT-supported macroinitiators, overcomes most of these shortcomings. However, it is limited only to vinyl and cyclic monomers (or living polymerization-active monomers). Therefore, it is still a big challenge for relevant scientists and engineers to functionalize CNTs in a simple, controllable manner with polycondensed polymers from corresponding monomers, instead of specific macromolecules possessing terminal functional groups.

In this work, we present an in situ polycondensation approach, bonding linear polyurea, polyurethane, and hyperbranched poly(urea-urethane) on amino-functionalized MWNTs (MWNT$\mathrm{NH}_{2}$ ) from commercially available polycondensation-type monomers. Our methodology can be regarded as a combination of grafting to and grafting from approaches because the monomers can grow from the tube surface, and the in situ formed oligomers and macromolecules can also synchronously couple with the tubes. This approach would pave the way for the functionalization of carbon nanotubes with polycondensed polymeric engineering plastics. 
Interestingly, the resulting polyurea-coated MWNTs can show self-assembly behaviors, forming flat- or flowerlike morphologies in the solid state. Moreover, after the polyurea was covalently grafted onto the tube surfaces, the D and G bands assigned to MWNTs were strongly attenuated, as confirmed by both general and confocal Raman spectroscopy measurements. This is possibly attributed to the energy transfer between the coated polyurea and the tubes.

\section{Experimental Procedures}

Materials. The CVD-MWNTs used in this work were purchased from Tsinghua-Nafine Nano-Powder Commercialization Engineering Centre in Beijing; the purity is higher than $95 \%$. Thionyl chloride $\left(\mathrm{SOCl}_{2}\right)$, diisocyanates, diamines, diols, and diethanolamine were obtained from Aldrich and used as received.

Instrumentation. Fourier transform infrared (FTIR) spectra were recorded on a PE Paragon 1000 spectrometer. Hydrogen nuclear magnetic resonance $\left({ }^{1} \mathrm{H} \mathrm{NMR}\right)$ spectra were measured with a Bruker $500 \mathrm{MHz}$ spectrometer. Transmission electron microscopy (TEM) studies were performed on either a Hitachi $\mathrm{H} 7100$ electron microscope operating at $100 \mathrm{kV}$ or a JEOL JEM 2200FS electron microscope (equipped with a JEOL energy dispersive spectrometer (EDS)) operating at $200 \mathrm{kV}$, respectively. Scanning electron microscopy (SEM) images were recorded using a LEO 1530-CBW field-emission microscope, and the samples were precoated with a homogeneous gold layer by sputtering technology. Raman spectra were recorded on a LabRam-1B Raman spectroscope excited at $514.5 \mathrm{~nm}$. Confocal Raman spectra and images were measured and obtained by $\mathrm{He}-$ $\mathrm{Ne}$ laser excitation at $632.8 \mathrm{~nm}$ with an excitation density of about $250 \mathrm{~kW} / \mathrm{cm}^{2}$. Molecular weights were measured by gel permeation chromatography (GPC) using PE Series 200 with PS as the standard and $\mathrm{DMF} / \mathrm{LiBr}$ as the eluent. Thermal gravimetric analysis (TGA) was conducted on a PE TGA-7 instrument at a heating rate of $20^{\circ} \mathrm{C} / \mathrm{min}$ in a nitrogen flow $(10 \mathrm{~mL} / \mathrm{min})$.

Acid Treatment of MWNTs. ${ }^{3}$ Typically, $12.0 \mathrm{~g}$ of crude MWNTs, $100 \mathrm{~mL}$ of $60 \% \mathrm{HNO}_{3}$, and $300 \mathrm{~mL}$ of $98 \% \mathrm{H}_{2} \mathrm{SO}_{4}$ was added into a $1000 \mathrm{~mL}$ flask equipped with a condenser with vigorous stirring. The flask was then immersed in a sonication bath $(40 \mathrm{kHz})$ for $10 \mathrm{~min}$. The mixture was then stirred for 100 min under reflux $\left(90-133^{\circ} \mathrm{C}\right)$. During this period, dense brown gas was collected and treated with a $\mathrm{NaOH}$ aqueous solution connected to the condenser by a plastic tube. After cooling to room temperature, the reaction mixture was diluted with $500 \mathrm{~mL}$ of deionized water and then vacuumfiltered through a filter paper (Fischer). The solid was dispersed in $500 \mathrm{~mL}$ of water and filtered again, and then $200 \mathrm{~mL}$ of water was used to wash the filtrate several times. The dispersion, filtering, and washing steps were repeated until the $\mathrm{pH}$ of the filtrate reached 7 (at least four cycles were required). The filtered solid was then washed with ca. $200 \mathrm{~mL}$ of acetone and THF 5 times to remove most of the water from the sample and dried under vacuum for $24 \mathrm{~h}$ at $60{ }^{\circ} \mathrm{C}$, giving $7.2 \mathrm{~g}$ ( $\sim 60 \%$ yield with the whole added crude MWNTs, $12 \mathrm{~g}$, as the reference).

Synthesis of MWNT-NH ${ }_{2}{ }^{7,8}$ Amino group functionalized MWNTs were synthesized as follows. The as-prepared MWNT$\mathrm{COOH}$ was reacted with excess neat $\mathrm{SOCl}_{2}$ for $24 \mathrm{~h}$ under reflux, and then the residual $\mathrm{SOCl}_{2}$ was removed by reducedpressure distillation equipped with a liquid nitrogen trap, giving acyl chloride-functionalized MWNTs (MWNT-COCl). The asproduced MWNT-COCl, without further purification and other
TABLE 1: Functionalization of MWNTs with Polyurea by In Situ Polycondensation of MDI and 1,6-Diaminohexane

\begin{tabular}{cccccc}
\hline code & $R_{\text {feed }}$ & $f_{\mathrm{wt}} \%$ & ${\text { thickness }(\mathrm{nm})^{a}}^{a}$ & $M_{\mathrm{n}}{ }^{b}$ & PDI \\
\hline NTPU1 & $1: 0.95$ & 30 & 2.8 & 1500 & 8.1 \\
NTPU2 & $1: 0.98$ & 50 & 5.3 & 3600 & 6.5 \\
NTPU3 & $1: 1.0$ & 72 & 7.5 & 8500 & 3.4
\end{tabular}

${ }^{a}$ The average thickness of the coated polymer layer detected by TEM. ${ }^{b}$ The number-average molecular weight of the polyurea collected from the reaction solution, measured by GPC with $\mathrm{DMF} / \mathrm{LiBr}$ as eluent.

treatments, was immediately reacted with excess 1,6-diaminohexane at $20-25^{\circ} \mathrm{C}$ for $24 \mathrm{~h}$ and then at $65-75^{\circ} \mathrm{C}$ for $24 \mathrm{~h}$ in the presence of triethylamine and 4-(dimethylamino)pyridine, obtaining amino-functionalized MWNTs $\left(\mathrm{MWNT}-\mathrm{NH}_{2}\right)$ after repeated filtration, washing, and vacuum-drying. The product contained ca. $0.93 \mathrm{mmol}$ of amino groups per $\mathrm{g}$ of carbon calculated from TGA data (ca. $12 \%$ weight loss). IR $\left(\mathrm{cm}^{-1}\right)$ : 3412, $3241\left(-\mathrm{NH}_{2}\right), 2917,2851\left(-\mathrm{CH}_{2}-\right), 1632$ (-CONH-).

Coating Polycondensed Polymers onto MWNTs by the In Situ Polycondensation Approach. Typically (NTPU3 Table 1), MWNT- $\mathrm{NH}_{2}(91 \mathrm{mg}$ ) and $N, N$-dimethylacetamide (DMAc, $50 \mathrm{~mL}$ ) were placed in a flask that was immersed in an ice/ water bath. With stirring, 4,4'-methylenebis(phenylisocyanate) (MDI, $1.109 \mathrm{~g}$ ) was added to the flask. The temperature was maintained at $0-5{ }^{\circ} \mathrm{C}$ for $4 \mathrm{~h}$ and $40{ }^{\circ} \mathrm{C}$ for $24 \mathrm{~h}$ and then subsequently reduced to $0-5^{\circ} \mathrm{C}$. Then, 1,6 -diminohexane $(0.515$ g) was added, whereupon the viscosity of the mixture increased dramatically. The mixture was maintained at $0-5{ }^{\circ} \mathrm{C}$ for $5 \mathrm{~h}$, followed by room temperature $\left(18-25^{\circ} \mathrm{C}\right)$ for $24 \mathrm{~h}$. DMAc $(150 \mathrm{~mL})$ was added to the flask to dilute the reaction mixture. After vacuum filtering, efficient washing with DMAc, redispersing in DMAc, and precipitating by the addition of THF, subsequent filtering, and freeze-drying, as treated in the grafting from approach, ${ }^{7} 270 \mathrm{mg}$ of gray polyurea-coated MWNTs (NTPU3) was obtained. TGA measurements showed that the grafted polymer weight proportion $\left(f_{\mathrm{wt}} \%\right)$ was $72 \%$.

Mixing of MWNT-NH $\mathrm{N}_{2}$ with Polyurea and Removal of Polyurea. To confirm that the ungrafted polymer can be efficiently removed from the MWNT-polyurea product by filtering and washing, the parallel experiment was done as follows. A total of $40 \mathrm{mg}$ of MWNT- $\mathrm{NH}_{2}$ and $400 \mathrm{mg}$ of polyurea $\left(M_{\mathrm{n}}=8500, \mathrm{PDI}=3.4\right)$ in $20 \mathrm{~mL}$ of DMAc was added to a $50 \mathrm{~mL}$ flask. The mixture was stirred for $24 \mathrm{~h}$ at room temperature. The solid product was collected after 4 times of repeated filtering, washing with DMAc, and redispersing in DMA and then was vacuum-dried, as treated in the synthesis of MWNT-polyurea. TGA measurements showed that the adsorbed polymer content is lower than 4 wt $\%$.

\section{Results and Discussion}

Synthesis and Characterization of MWNT-Polyurea. The in situ polycondensation approach to functionalization of CNTs is schematically shown in Figure 1 . To confirm the generality and versatility of this approach, we employed MDI or 1,6diisocyanatohexane (HDI) to react with various diamines $\left(\mathrm{H}_{2} \mathrm{~N}\right.$ $\left.\left(\mathrm{CH}_{2}\right)_{n} \mathrm{NH}_{2}, n=2,4,6\right)$ or diols $\left(\mathrm{HO}\left(\mathrm{CH}_{2}\right)_{n} \mathrm{OH}, n=2,4,6\right)$, growing a series of polycondensed polymers onto MWNTs (see Figure 1A). Significantly, if diethanolamine was reacted with MDI or other diisocyanates, multihydroxy hyperbranched poly(urea-urethane)s would be covalently tethered onto MWNT surfaces without gelation. ${ }^{9}$ Such molecular nanohybrids associated with plenty of hydroxyl groups on the tube periphery will 


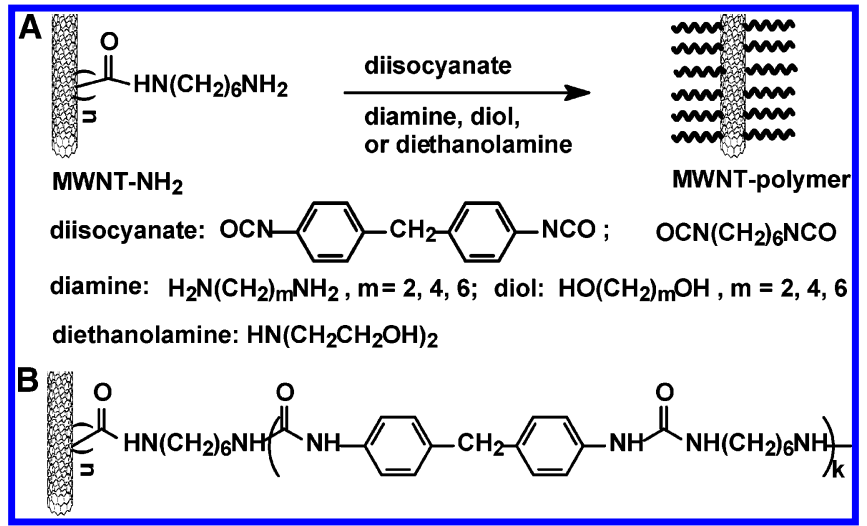

Figure 1. Schematic illustration for the functionalization of carbon nanotubes by the in situ polycondensation approach (A) and the chemical structure of the MWNT-polyurea made from MDI and 1,6diaminohexane (B).

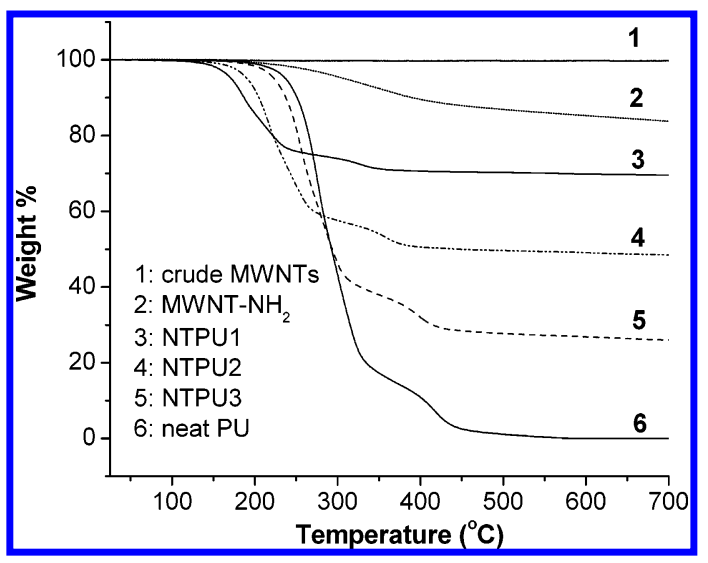

Figure 2. TGA weight loss curves of crude MWNTs (1), MWNT$\mathrm{NH}_{2}$ (2), NTPU1 (3), NTPU2 (4), NTPU3 (5), and neat polyurea (6).

have applications in nanoengineering and nanofabrication, especially for templating and further functionlization. ${ }^{10}$ In this paper, we focus on the preparation and characterization of MWNT-polyurea nanohybrids. The corresponding reaction conditions and selected results for the polycondensation of MDI and 1,6-diminohexane are summarized in Table 1. The chemical structure of the resulting nanohybrids is schematically illustrated in Figure 1B.

It is generally accepted that in polycondensation processes, the resulting molecular weight (MW) of the polymer depends mainly on the molar feed ratio of the reactive functional groups. Hence, we engineered our experiment to control the MW or $f_{\mathrm{wt}} \%$ of polyurea by adjusting the feed ratio of isocyanato/amino groups $\left(R_{\text {feed }}\right)$. Indeed, $f_{\mathrm{wt}} \%$, calculated from TGA weight loss curves (see Figure 2), can be well-controlled by adjusting the $R_{\text {feed }}$. Moreover, the greater the $f_{\mathrm{wt}} \%$, the higher the MW of the ungrafted polyurea collected from the solution. ${ }^{11}$ From the TGA curves, we can also see that the decomposition temperature $\left(T_{\mathrm{d}}\right)$ of the grafted polyurea increases with increasing grafted content. This is in accordance with the MW increasing tendency.

It was noteworthy that the adsorbed polyurea can be efficiently removed from the products by filtration and washing as mentioned in the Experimental Procedures. The parallel experiment, in which MWNT- $\mathrm{NH}_{2}$ was mixed with free polyurea in DMAc solvent followed by efficient filtration and washing, proved that the adsorbed polyurea quantity was lower than $4 \mathrm{wt} \%$. Furthermore, NMR measurement for the upper layer of DMSO- $d_{6}$ solution, collected by centrifuging $(2 \mathrm{~h}$ at a rate of $6000 \mathrm{rpm}$ ) of NTPU3 dispersed in the DMSO- $d_{6}$, showed that no polyurea signals appeared in the spectrum. This further

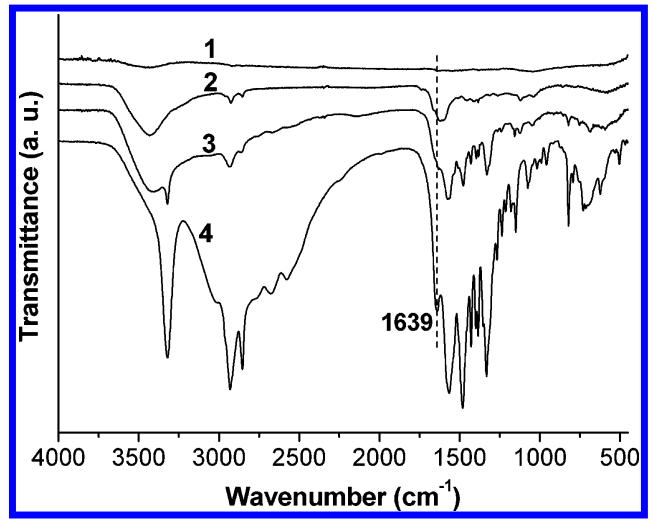

Figure 3. FTIR spectra of crude MWNTs (1), NTPU1 (2), NTPU2 (3), and NTPU3 (4).

indicated that the adsorbed polymer quantity was negligible. Therefore, the in situ polycondensation approach presented here promised the grafting of polycondensed polymers onto CNT surfaces with some extent of control. Although the CNTs/ polymer composites have also been reported to be made by in situ polymerization of monomers in the presence of CNTs, the grafted-polymer proportion on the tubes was rarely measured by separation of polymer-grafted CNTs from the as-prepared composite mixture. ${ }^{12}$ Thus, the covalent grafting efficiency and capacity of this method were rarely evaluated previously.

The molecular composition of the resulting MWNT-polyurea nanohybrids was confirmed by FTIR and ${ }^{1} \mathrm{H}$ NMR measurements. ${ }^{13}$ For NTPU1-3, the characteristic absoption peaks of polyurea such as $-\mathrm{NHCONH}-,-H N C O N H$-, and $-\mathrm{CH}_{2}$ - clearly appeared at 1639,3320 , and $2930 / 2853 \mathrm{~cm}^{-1}$, respectively. The benzene-ring $\mathrm{C}=\mathrm{C}$ absorption peak of polyurea made with MDI at ca. $1600 \mathrm{~cm}^{-1}$ was overshadowed by that of amido groups at $1565 \mathrm{~cm}^{-1}$, while the corresponding peak at $1480 \mathrm{~cm}^{-1}$ was very strong (see Figure 3). The greater the grafted amount, the stronger the absorption peaks.

Polymer-functionalized CNTs would show much higher solubility or better dispersibility as compared with pristine nanotubes. Herein, as polyurea is polar, our resulting samples of MWNT-polyurea are readily dispersed in polar organic solvents such as dimethyl sulfoxide (DMSO), N,N-dimethylformamide (DMF), 1-methyl-2-pyrrolidinone (NMP), and DMAc.

Structure and Morphology of the Resulting MWNTPolyurea Molecular Nanocomposites. The fine nanostructures of the as-prepared CNT-polyurea nanocomposites were investigated by TEM. As shown in Figure 4A-D, a core-shell structure with MWNTs at the center can be clearly observed for the nanocomposites, indicating that the MWNTs were coated by a layer of polymer chains. ${ }^{3,14}$ From the TEM images of the NTPU3-NTPU1 samples, we can clearly discern that the higher the quantity of the grafted polymer, the thicker the polymer shell. Such a core-shell structure can be called a molecular nanocomposite because of a covalent linkage between the core and the shell. As a comparison, such core-shell structures were not found for the MWNTs/polyurea mixtures. For the crude MWNTs, the tube surface is relatively smooth and clean (Figure $4 \mathrm{E}$ ), obviously different from that of the polymer-functionalized MWNTs.

EDS elemental measurements that enable us to detect the elemental contents were conducted for the CNT-polyurea nanohybrids as a support for the TEM results. Nevertheless, EDS mapping analyses require sufficient EDS scan cycles (five to ten cycles are generally needed, depending on the specifically detectable X-ray intensity eradiated from the sample) to produce 


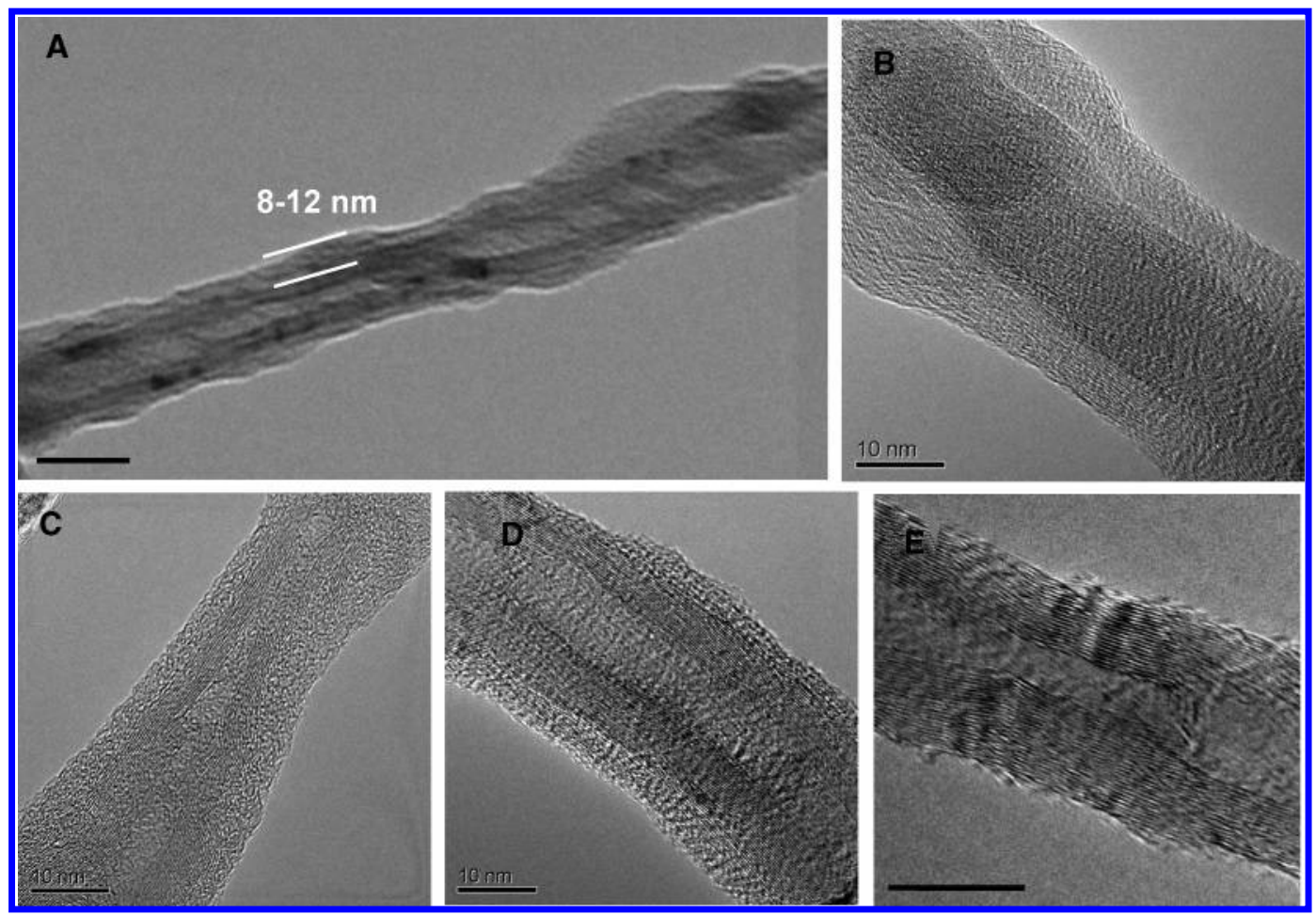

Figure 4. Representative TEM images of NTPU3 (A and B), NTPU2 (C), NTPU1 (D), and a crude MWNT (E). The scale bar represents 25 (in panel A) and $10 \mathrm{~nm}$ (in panels $\mathrm{B}-\mathrm{E}$ ), respectively.

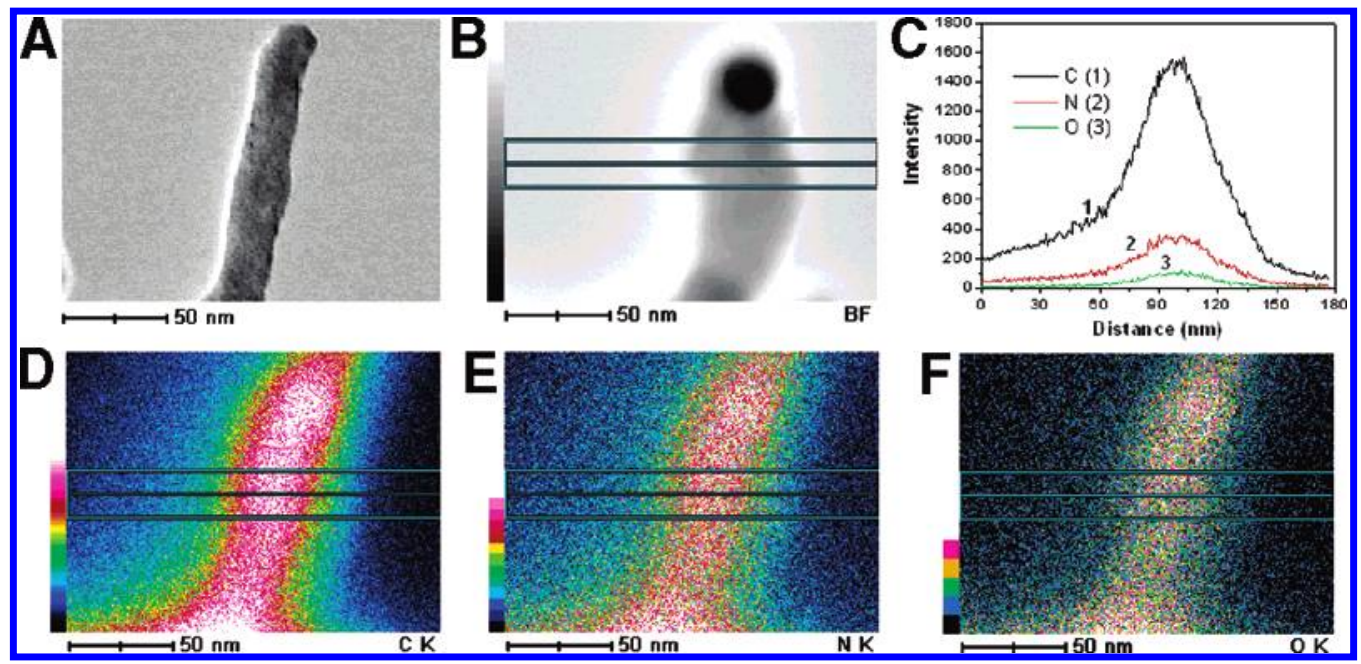

Figure 5. EDS analysis results for NTPU2. (A) Functionalized tube image before mapping. (B) Tube profile after 5 times of scanning. (C) Section analysis spectrum of $\mathrm{C}, \mathrm{N}$, and $\mathrm{O}$ elements. $(\mathrm{D}-\mathrm{F}) \mathrm{C}, \mathrm{N}$, and $\mathrm{O}$ element mapping profiles, respectively.

a reliable spectrum. The highly focused electron beam used in the EDS analyze can distort or even damage the polyureafunctionalized CNTs, possibily due to the combination of electron beam irradiation effects and the in situ generated nitrogen and oxygen radicals from the decomposition of the coated polyurea. For the tubes coated with higher amounts of polyurea, only a subsequent EDS scan during mapping analysis would destroy or distort the tubes. Hence, it is very difficult to collect the reliable EDS mapping profile for such tubes, although a significant amount of attempts was made. Figure 5 displays the EDS mapping results of a chosen tube with a thin polymer layer. The straight tube (Figure 5A) was irradiated into a twisted and swollen one (Figure 5B) after five cycles of EDS scanning. The line-scan elemental analysis (Figure 5C), obtained from the section analysis on part of the tube (marked as green lines in Figure 5B), indicates that the sample contains carbon (C), nitrogen $(\mathrm{N})$, and oxygen $(\mathrm{O})$ elements. The intensity of the nitrogen element is obviously higher than that of oxygen, which is in agreement with the composition of polyurea made from MDI and 1,6-diminohexane (the mole ratio of nitrogen to oxygen is ca. 2:1 for the neat polyurea). The mapping results (Figure 5D-F) show that the dispersions of carbon, nitrogen, and oxygen elements conform well with the shape of the polymer-grafted carbon nanotube.

The morphology of the resulting MWNT-polyurea nanocomposites was observed with SEM (see Figure 6). The nanocomposites showed behavior associated with self-assembly, particularly in the case of MWNTs bonded with high quantities of polyurea, which resulted in leaf-, flat-, and flowerlike structures. For NTPU1 with $30 \mathrm{wt} \%$ of polyurea, the rodlike structures ${ }^{7,14}$ and an organization tendency can be clearly observed (Figure 6B), as compared with the crude MWNTs (Figure 6A). A few hybrids were assembled together along the tube axes, generating regular hollow grooved flat-structures (Figure 6C). With 


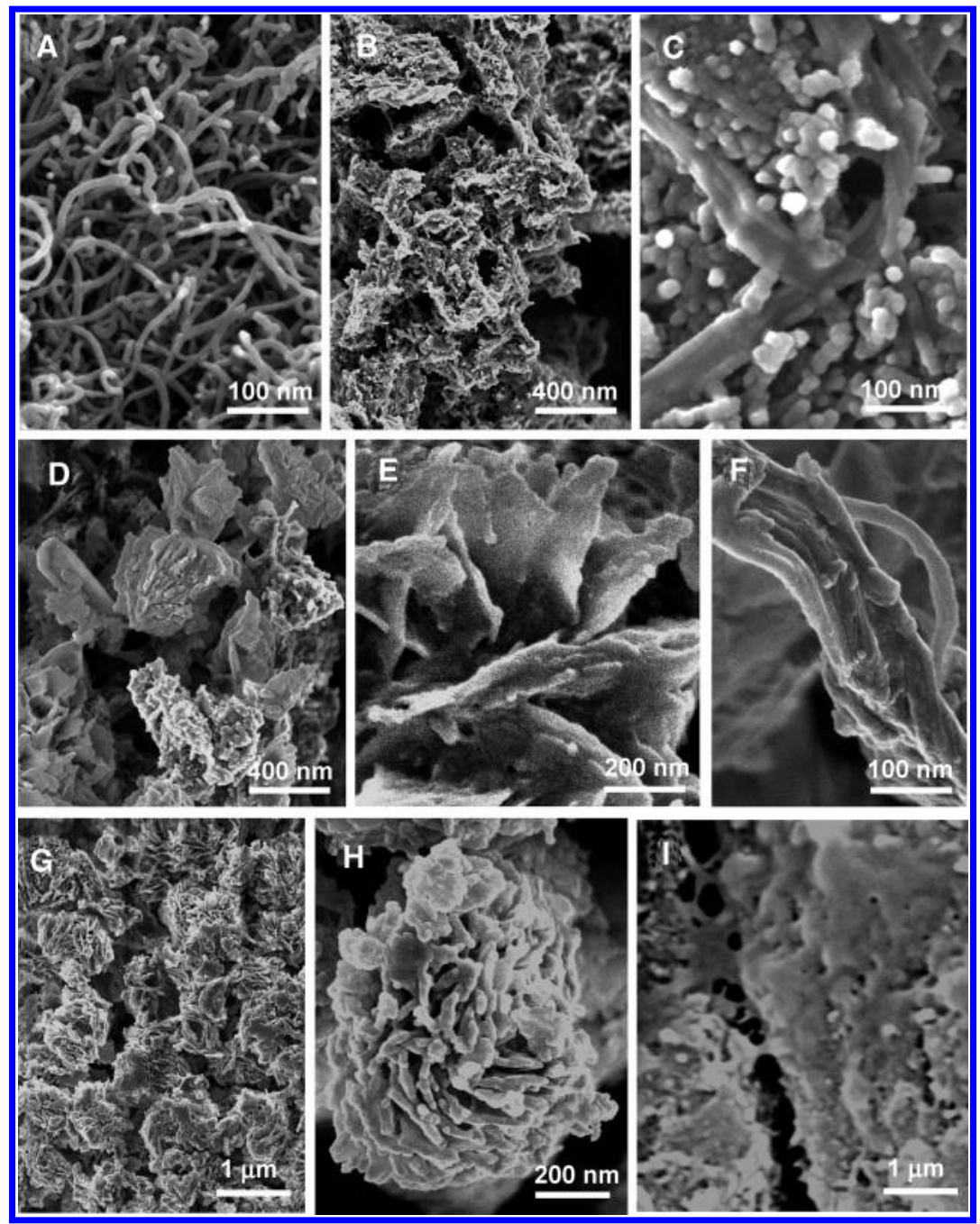

Figure 6. Representative SEM images of crude MWNTs (A), NTPU1 (B and C), NTPU2 (D-F), NTPU3 (G and H), and the sample obtained by direct drying DMF solution of NTPU3 (I).

increasing polyurea content, most of the functionalized tubes appear to form arc-, flat-, and flowerlike structures (Figure $6 \mathrm{D}, \mathrm{E})$. Figure $6 \mathrm{~F}$ displays a section of a self-assembled flat structures, in which the functionalized nanotubes are aligned and organized parallel. One tube, not included totally in the aggregate, is clearly presented. It is evidently thicker than crude tubes because of the polymer coating. The sample of NTPU3 with $72 \%$ polyurea resulted in beautiful $\mu \mathrm{m}$ scale roselike flowers constructed from individual MWNT-polyurea molecular hybrids (Figure 6G,H). Precipitation appears to provide the impetus for this self-assembly process because these structures were destroyed when solvent was added (Figure 6I), but the structures were reformed by adding the nanohybrid DMF solution to THF. Phase separation, macromolecular chain entanglement, and other interactions during the precipitation, with the support of stiff tube bars, can favor this organization of nanostructures. ${ }^{15}$ Further detailed study of the self-assembly mechanism and the parameters governing these processes are in progress.

Raman Spectroscopy. Raman spectroscopy is a powerful tool used to characterize the functionalized CNTs. As shown in Figure 7 (514.5 $\mathrm{nm}$ excitation), the D- and G-bands of MWNTs at ca. 1350 and $1582 \mathrm{~cm}^{-1}$, attributed to the defects and disorder-induced modes and in-plane $E_{2 g}$ zone-center mode, are clearly observed for both crude MWNTs and some functionalized MWNTs (MWNT-COOH and MWNT-NH 2$).{ }^{16}$ The D- to G-band intensity ratios $\left(I_{\mathrm{D}} / I_{\mathrm{G}}\right)$ for $\mathrm{MWNT}-\mathrm{COOH}$ and
MWNT- $\mathrm{NH}_{2}$ are ca. 1.11 and 1.09 , respectively. These ratios are greater than that of pristine MWNTs (ca. 0.81). In addition, the $\mathrm{D}^{\prime}$-band at $1617 \mathrm{~cm}^{-1}$, which is known to be directly affected by the disorder in nanotubes, also exhibits different relative intensities for pristine and modified MWNTs. This band can be barely observable in pristine tubes but is clearly detectable after functionalization, indicating an increase in defects along the tube body. ${ }^{16}$ For NTPU1, the D- and G-bands are also clearly observed (Figure 7A, spectrum 4), but the relative peak intensity is lower than that of MWNT- $\mathrm{NH}_{2}$. Significantly, all these characteristic absorption peaks were strongly attenuated or almost disappeared after a high amount of polyurea was tethered to the surfaces of MWNTs for NTPU3 (Figure 7A, spectrum 5). Furthermore, the Raman signals assigned to pure polyurea were not found in the spectrum of NTPU3 either.

To explore the novel phenomenon aforementioned, we measured Raman spectra of the mechanical mixtures of MWNTs and polyurea with different polyurea contents (Figure 7B). The Raman signals of the mechanical mixture with 30 wt \% of polyurea were similar to those of crude MWNTs, and the Dand G-bands appeared at 1350 and $1581 \mathrm{~cm}^{-1}$, respectively. For the mixture with $72 \mathrm{wt} \%$ content of polyurea, both nanotube and polyurea signals were observed (the CNT bands blue-shifted by about 7-10 wavenumbers). This is significantly different from the Raman signals of NTPU3, although the polyurea fraction in the composites is the same $(72 \%)$, which suggests that the polymer-grafted CNTs are completely different from 


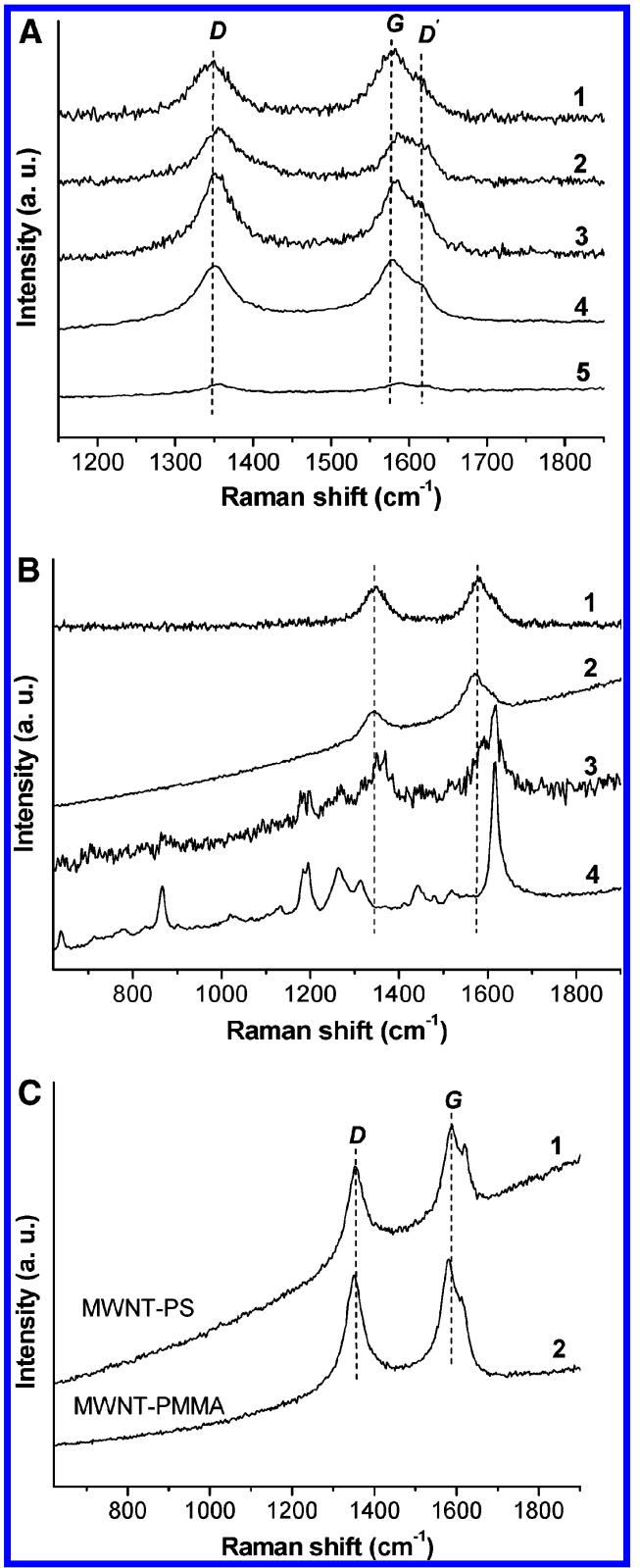

Figure 7. (A) Raman spectra of crude MWNTs (1), MWNT-COOH (2), MWNT-NH 2 (3), NTPU1 (4), and NTPU3 (5). (B) Raman spectra of crude MWNTs (1), mixture sample Mix-1 with 30 wt $\%$ of polyurea (2), mixture sample Mix-2 with 72 wt $\%$ of polyurea (3), and neat polyurea (4). (C) Raman spectra of MWNT-PS with 85 wt $\%$ of polystyrene (1) and MWNT-PMMA with 80 wt \% of PMMA (2).

CNTs/polymer mixtures in terms of Raman characteristics. For the covalently functionalized CNTs, the polymer is individually anchored to the tube surface, forming a nanoscale (ca. 2-15 $\mathrm{nm}$, dependent on polymer amount) layer of coverage, especially in the cases of higher grafting-polymer proportions. Such coverage may lead to three different phenomena in the Raman measurements: (1) only CNT signals are detectable if the polymer layer is transparent, (2) only polymer signals are present if the polymer layer can absorb and reflect the whole excited energy, and (3) no signals or strong photoluminescence can be observed if there is energy transfer between nanotubes and polymer chains or if the coated polymer makes the electronic property of CNTs changed. The covered polymer layer that is only a few nanometers thick forms noncontinuous structures as a result of random defects on the tube surface. This makes it difficult or even impossible to totally absorb and reflect all the excited energy for the polymer phase. Therefore, the Raman signals of polymer chains are difficult to detect if the polymer is tethered to the nanotubes, and generally, only the CNT signals are found. By contrast, because the two macroscopic phases of CNTs and polymers exist individually in the mechanical mixture, the Raman signals of both components can be observed.

Another possible explanation for the reduced Raman signal of the polymer-grafted CNTs is the low CNT content. To eliminate this query, we covalently grafted other polymers, such as polystyrene (PS) and poly(methyl methacrylate) (PMMA), onto the tube surfaces with different polymer contents (regarding how to covalently grow PMMA or PS on the MWNT surfaces to prepare MWNT-PMMA or MWNT-PS, see the previous references ${ }^{3 \mathrm{a}, 7}$ ), to investigate the effects of polymer proportions on the Raman signals of nanocomposites. It was found that the polymer content has almost no influence on the Raman signal intensity of CNTs. Strong D- and G-bands of CNTs were observed, while the samples with a polymer fraction were as high as $80-85 \mathrm{wt} \%$ (note: this value is much higher than that of NTPU3, 72\%) (see Figure 7C). ${ }^{17}$ The polymer signals were not found yet, and the $\mathrm{D}^{\prime}$-band was relatively stronger than that of pristine CNTs. On the other hand, the query of chemical modification destroying the CNT structure can be also excluded because the same batch of MWNT-COOH was employed as the material for all the CNT-polymer samples. Therefore, the Raman signal decrease of CNTs for the samples of MWNTpolyurea (especially for NTPU3) was not caused by either the low content of CNT or the nontransparence of polyurea but was possiblly due to the energy transfer between CNTs and polyurea or the grafted polymer influence on the electronic properties of CNTs. A possible application of this phenomenon is the fabrication of luminescent/energy-absorption materials and devices.

These results were further confirmed by confocal Raman spectroscopy ( $\mathrm{He}-\mathrm{Ne}$ laser at $632.8 \mathrm{~nm}$, an excitation density of about $250 \mathrm{~kW} / \mathrm{cm}^{2}$ ) (see Figure 8). For NTPU1, distinct fluorescence background appeared in the Raman spectrum (Figure 8A), and it gradually became weaker as the irradiation time was increased from 10 to $400 \mathrm{~s}$. In the same spectrum, two peaks at 1291.3 and $1548.9 \mathrm{~cm}^{-1}$ were observed, which can be assigned to the D- and G-bands of CNTs with significant red shifts of 60 and $32 \mathrm{~cm}^{-1}$, respectively. In the Raman spectrum of NTPU3 (Figure 8B), the fluorescence background was also observed, and it also decreased with increasing irradiation time. However, the D- and G-bands of CNTs were too small to be clearly detected for NTPU3. As a comparison, the D- and G-bands of CNTs for the crude MWNTs (Figure 8C) and MWNT-PS (Figure 8D) or MWNT-PMMA (the spectrum was not shown here) were very strong, and almost no fluorescence background was found. The confocal Raman results are in accordance with those of the bulk Raman measurements. This provides us with the following conclusions: (1) the Raman signal of polymer-functionalized MWNTs is strongly dependent on the grafted polymer species and their structures, (2) the effects of polymer content on the Raman signals of functionalized nanotubes are inconclusive: strong in some cases, while neglectable for others, and (3) if a high content of polymer has affected the Raman signals, it is not because the CNTs content is too low to be detected but because the tubes are wrapped by the polymer chains that may result in energy transfer between tubes and polymers.

Sun et al. ${ }^{4,18}$ reported the fluorescence emission phenomenon of polymer-functionalized CNTs during Raman measurements. On the basis of their experiments and results, they concluded that the luminescence interference is dependent on the dispersion 


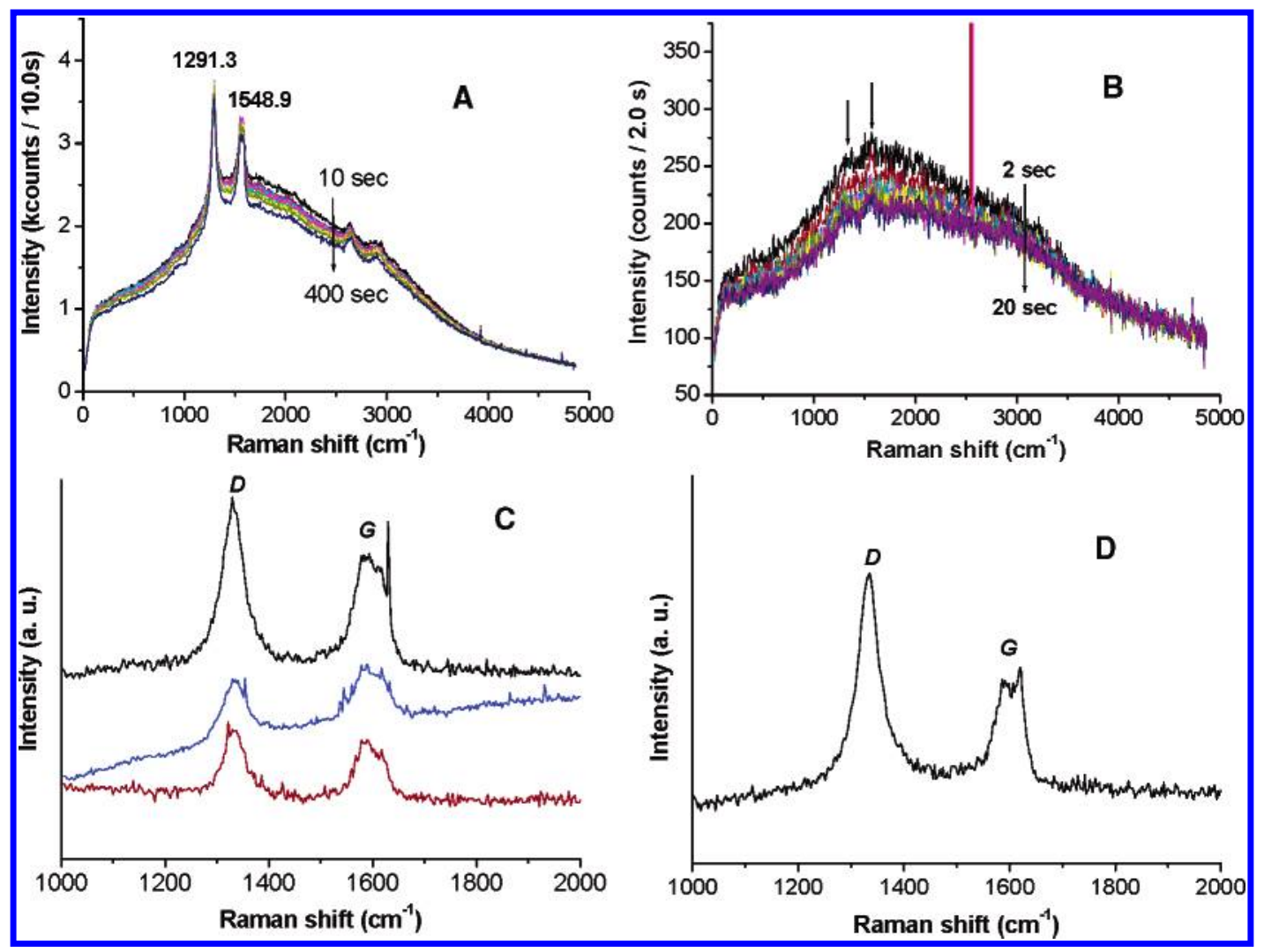

Figure 8. Repsesentative confocal Raman spectra excited at $632.8 \mathrm{~nm}$ of NTPU1 (A), NTPU3 (B), crude MWNTs excited at different spots (C), and MWNT-PS (D). The corresponding confocal Raman images are not shown.

of the carbon nanotubes in the soluble sample. Herein, we further revealed that the Raman signals of functionalized CNTs are strongly dependent on the given polymers and their structures. However, detailed studies are needed to fully understand the effect of polymer coating on CNTs in terms of Raman spectra and the possible energy transferring mechanism.

\section{Conclusions}

MWNTs were covalently functionalized with polyureas by the in situ polycondensation strategy. The grafted polymer content can be controlled by adjusting the feed ratio of polycondensation-type monomers. Furthermore, this approach can be easily extended to other polycondensation systems, binding polycondensation-type polymers such as polyurethane, polyamide, and polyester to the carbon nanotube surfaces. The simplicity and versatility of this approach open new avenues for the functionalization and application of nanomaterials and nanocomposites. Core-shell nanostructures can be observed by TEM, indicating that the polymer chains are evenly grafted onto the tubes. The polyurea-coated MWNTs can self-assemble into arc-, flat-, or rose flowerlike structures, which probably provide a new element for supramolecular chemistry. Moreover, the Raman signals of CNTs were strongly weakened after the polyurea was coated onto the carbon nanotubes. Comparison experiments and confocal Raman scpectroscopy measurements indicated that the Raman signals of polymer-functionalized CNTs are essentially dependent on the given polymer species and their structures but not the polymer content.

Acknowledgment. We acknowledge financial support from the EPSRC, the National Natural Sciences Foundation of China (50473010 and 20304007), Fok Ying Tung Education Foundation (91013), and Rising-Star Program Foundation of Shanghai (03QB14028).

\section{References and Notes}

(1) (a) Chen, J.; Hamon, M. A.; Hu, H.; Chen, Y.; Rao, A. M.; Eklund, P. C.; Haddon, R. C. Science 1998, 282, 95-98. (b) Chen, X.; Armes, S. P. Adv. Mater. 2003, 15, 1558-1562. (c) Mori, H.; Müller, A. H. E. Top. Curr. Chem. 2003, 228, 1-37. (d) Ajayan, P. M. Chem. Rev. 1999, 99, 1787-1799. (e) Dai, H. Acc. Chem. Res. 2002, 35, 1035-1044. (f) Hirsch, A. Angew. Chem., Int. Ed. 2002, 41, 1853-1859. (g) Liu, J.; Rinzler, A. G.; Dai, H. J.; Hafner, J. H.; Bradley, R. K.; Boul, P. J.; Lu, A.; Iverson, T.; Shelimov, K.; Huffman, C. B.; Rodriguez-Macias, F.; Shon, Y. S.; Lee, T. R.; Colbert, D. T.; Smalley, R. E. Science 1998, 280, 1253-1256.

(2) (a) Iijima, S. Nature 1991, 354, 56-58. (b) Iijima, S.; Ichihashi, T. Nature 1993, 363, $\overline{603-605 . ~}$

(3) (a) Kong, H.; Gao, C.; Yan, D. J. Am. Chem. Soc. 2004, 126, $412-$ 413. (b) Xu, Y.; Gao, C.; Kong, H.; Yan, D.; Jin, Y. Z.; Watts, P. C. P. Macromolecules 2004, 37, 8846-8853.

(4) Sun, Y.-P.; Fu, K.; Lin, Y.; Huang, W. Acc. Chem. Res. 2002, 35, $1096-1104$.

(5) For example, see (a) Qin, S.; Qin, D.; Ford, W. T.; Resasco, D. E.; Herrera, J. E. J. Am. Chem. Soc. 2004, 126, 170-176. (b) Shaffer, M. S.; Koziol, K. Chem. Commun. 2002, 2074-2075. (c) Yao, Z.; Braidy, N.; Botton, G. A.; Adronov, A. J. Am. Chem. Soc. 2003, 125, 16015-16024. (d) Cao, L.; Yang, W.; Yang; J.; Wang, C.; Fu, S. Chem. Lett. 2004, 33, 490-491. (e) Liu, Y. Q.; Adronov, A. Macromolecules 2004, 37, 47554760. (f) Wu, W.; Zhang, S.; Li, Y.; Li, J.; Liu, L.; Qin, Y.; Guo, Z.-X.; Dai, L.; Ye, C.; Zhu, D. Macromolecules 2003, 36, 6286-6288. (g) Qin, S. H.; Qin, D. Q.; Ford, W. T.; Resasco, D. E.; Herrera, J. E. Macromolecules 2004, 37, 752-757. (h) Qin, S. H.; Qin, D. Q.; Ford, W. T.; Herrera, J. E.; Resasco, D. E.; Bachilo, S. M.; Weisman, R. B. Macromolecules 2004, 37, 3965-3967.

(6) (a) Huang, W.; Lin, Y.; Taylor, S.; Gaillard, J.; Rao, A. M.; Sun, Y.-P. Nano Lett. 2002, 2, 231-234. (b) Zhao, B.; Hu, H.; Haddon, R. C. Adv. Funct. Mater. 2004, 14, 71-76. (c) Zhang, W. D.; Shen, L.; Phang, I. Y.; Liu, T. X. Macromolecules 2004, 37, 256-259.

(7) Kong, H.; Gao, C.; Yan, D. Macromolecules 2004, 37, 4022-4030.

(8) Philip, B.; Xie, J.; Abraham, J. K.; Varadan, V. K. Polvm. Bull. 2005, 53, 127-138.

(9) Gao, C.; Yan, D. Macromolecules 2003, 36, 613-620.

(10) Gao, C.; Yan, D. Prog. Polvm. Sci. 2004, 29, 183-275.

(11) It was reported that in the controlled/living polymerization, the initiating sites linked to the solid surface have the same initiating efficiency 
as the free initiators in the solution. For example, see Matyjaszewski, K.; Miller, P. J.; Shukla, N.; Immaraporn, B.; Gelman, A.; Luokala, B. B.; Siclovan, T. M.; Kickelbick, G.; Vallant, T.; Hoffmann, H.; Pakula, T. Macromolecules 1999, 32, 8716-8724.

(12) For example, see (a) Park, C.; Ounaies, Z.; Watson, K. A.; Crooks, R. E.; Smith, J.; Lowther, S. E.; Connell, J. W.; Siochi, E. J.; Harrison, J. S.; Clair, T. L. S. Chem. Phvs. Lett. 2002, 364 (3-4), 303-308. (b) Harris, P. J. F. Inter. Mater. Rev. 2004, 49, 31-43. (c) Feng, W.; Bai, X. D.; Lian,

Y. Q.; Liang, J.; Wang, X. G.; Yoshino, K. Carbon 2003, 41, 1551-1557. (13) ${ }^{1} \mathrm{H}$ NMR (DMSO- $\left.d_{6}, 500 \mathrm{~Hz}\right): \delta 6.95-7.4(-\mathrm{Ar}-), 6.1(-\mathrm{NHCON} H$ ) $3.72\left(\mathrm{Ar}-\mathrm{CH}_{2}-\mathrm{Ar}\right), 2.9\left(-\mathrm{NHCH}_{2}-\right), 1.2-1.4 \mathrm{ppm},\left(-\mathrm{C}-\mathrm{CH}_{2}-\right)$.
(14) Kong, H.; Gao, C.; Yan, D. J. Mater. Chem. 2004, 14, 14011405 .

(15) Kong, H.; Li, W. W.; Gao, C.; Yan, D.; Jin, Y. Z.; Walton, D. R. M.; Kroto, H. W. Macromolecules 2004, 37, 6683-6686.

(16) Jorio, A.; Pimenta, M. A.; Souza Filho, A. G.; Saito, R.; Dresselhaus, G.; Dresselhaus, M. S. New J. Phvs. 2003, 5, 139.1-139.17.

(17) The other group observed the similar Raman results for their MWNT-PS or MWNT-PMMA samples. See, Baskaran, D.; Mays, J. W. Bratcher, M. S. Angew. Chem., Int. Ed. 2004, 43, 2138-2142.

(18) Riggs, J. E.; Guo, Z.; Carroll, D. L.; Sun, Y.-P. J. Am. Chem. Soc 2000, 122, 5879-5880. 